\title{
MOVIMENTOS ARTÍSTICOS CONTEMPORÂNEOS: ESTUDOS E ANÁLISES
}

\author{
Prof $^{a}$. Dr ${ }^{a}$. M ${ }^{a}$. Sílvia Barros de Held \\ PUC-Campinas
}

\section{Introdução ao problema}

No decorrer das aulas de Teorias da Arte, sentiu-se a necessidade de organizar os movimentos artísticos contemporâneos cronologicamente, além de contextualizá-los, a fim de facilitar o estudo e a compreensão dos mesmos, embora alguns movimentos tenham ocorrido concomitantemente. Para tanto, inicialmente, tomou-se por base a cronologia proposta por Frederico de Morais ${ }^{1}$.

Como os assuntos eram vastos para o tempo de aula destinado à disciplina e o interesse dos alunos pelo assunto ultrapassava as paredes da sala de aula, a proposta deste estudo foi apresentada e imediatamente, acolhida com entusiasmo por parte dos discentes.

Foi então solicitado a cada aluno do ano de $2003,1^{\circ}$ e $2^{\circ}$ semestres, o estudo de um dos cinqüenta movimentos artísticos apresentados, a partir do Neo Classicismo, à escolha de cada um, com a inserção de artistas relevantes e obras mais significativas de cada movimento, além da aplicação prática das características visuais específicas do movimento estudado a um trabalho prático, também individual, onde poderia, utilizar vários recursos, inclusive a computação gráfica.

A partir dos movimentos apresentados e dos trabalhos executados, decidiu-se pela extensão e aprofundamento do mesmo e sua posterior publicação - impressa e eletrônica, dada à carência de bibliografia específica e à importância do mesmo para os estudantes e profissionais da área de Artes Visuais e Design, além de outros segmentos correlatos.

\section{Metodologia}

A partir da proposta, a metodologia utilizada tem como base o método dedutivo, partindo-se do geral, tanto em termos de abordagem dos assuntos como em termos de participação dos alunos neste projeto.

Dentro do Grupo de Pesquisa "A Imagem: Arte e Design", na Linha de Pesquisa "Aspectos Contemporâneos da Imagem: Teoria e Prática”, houve a proposta de aprofundamento do estudo, a análise dos 
Movimentos Artísticos e a posterior divulgação do trabalho através de publicação impressa e eletrônica.

A partir dos estudos desenvolvidos inicialmente por cada aluno e com a concordância dos mesmos, eles transformam-se em co-autores (e responsáveis) por cada capítulo, no caso da publicação impressa, e também co-autores dos mesmos movimentos, divulgados através de verbetes, no caso da publicação eletrônica.

Houve então a necessidade de padronização de abordagem dos movimentos artísticos, tanto no caso dos textos e imagens para impressão dos trabalhos, como para a divulgação da apresentação de um glossário dos movimentos artísticos contemporâneos, composto de verbetes, através da mídia eletrônica.

A proposta deste projeto contempla os seguintes movimentos:

\begin{tabular}{|l|c|c|}
\hline ASSUNTO & ANO & $\begin{array}{c}\text { ORDEM } \\
\text { CRONOLÓGICA }\end{array}$ \\
\hline NEOCLASSICISMO & 1748 & 1 \\
\hline ROMANTISMO & 1777 & 2 \\
\hline ESCOLA BARBIZON & 1820 & 3 \\
\hline REALISMO & 1850 & 4 \\
\hline IMPRESSIONISMO & 1874 & 5 \\
\hline NABIS & 1880 & 6 \\
\hline NEO-IMPRESSIONISMO & 1885 & 7 \\
\hline SIMBOLISMO & 1888 & 8 \\
\hline ART NOUVEAU & 1890 & 9 \\
\hline FAUVISMO & 1905 & 10 \\
\hline EXPRESSIONISMO & 1905 & 11 \\
\hline CUBISMO & 1907 & 12 \\
\hline FUTURISMO & 1909 & 13 \\
\hline PINTURA METAFISICA & 1910 & 14 \\
\hline SUPREMATISMO & 1915 & 15 \\
\hline DADAISMO & 1916 & 16 \\
\hline DE STIJL & 1917 & 17 \\
\hline NEO PLASTICISMO & 1917 & 18 \\
\hline ORFISMO & 1918 & 19 \\
\hline
\end{tabular}




\begin{tabular}{|c|c|c|}
\hline BAUHAUS & 1919 & 20 \\
\hline CONSTRUTIVISMO & 1920 & 21 \\
\hline SURREALISMO & 1924 & 22 \\
\hline ART DECO & 1925 & 23 \\
\hline ARTE CONCRETA & 1930 & 24 \\
\hline ABSTRAÇÃO - CRIAÇÃO & 1931 & 25 \\
\hline $\begin{array}{l}\text { UNIVERSALISMO } \\
\text { CONSTRUTIVO }\end{array}$ & 1934 & 26 \\
\hline ARTE BRUT & 1945 & 27 \\
\hline GRUPO COBRA & 1948 & 28 \\
\hline $\begin{array}{l}\text { EXPRESSIONISMO } \\
\text { ABSTRATO }\end{array}$ & 1950 & 29 \\
\hline HAPPENING & 1952 & 30 \\
\hline TACHISMO & 1954 & 31 \\
\hline ARTE CINÉTICA & 1955 & 32 \\
\hline POP ART & 1956 & 33 \\
\hline OP ART & 1960 & 34 \\
\hline NOVO REALISMO & 1960 & 35 \\
\hline FLUXUS & 1962 & 36 \\
\hline VIDEO ART & 1963 & 37 \\
\hline MINIMAL ART & 1965 & 38 \\
\hline ARTE COMPUTADOR & 1968 & 39 \\
\hline HIPERREALISMO & 1968 & 40 \\
\hline TROPICALISMO & 1968 & 41 \\
\hline ARTE CONCEITUAL & 1969 & 42 \\
\hline ARTE POVERA & 1969 & 43 \\
\hline FOTO LINGUAGEM & 1970 & 44 \\
\hline ARTE POSTAL & 1970 & 45 \\
\hline BODY ART & 1970 & 46 \\
\hline GRAFITI & 1975 & 47 \\
\hline TRANSVANGUARDA & 1977 & 48 \\
\hline NEO-EXPRESSIONISMO & 1980 & 49 \\
\hline SIMULACIONISMO & 1987 & 50 \\
\hline
\end{tabular}




\section{Para publicação impressa:}

De acordo com os trabalhos apresentados pelos alunos (em disquetes e impressos), organização cronológica dos Movimentos Artísticos;

Padronização da apresentação do estudo e análise de cada movimento, dentro do seguinte formato:

Panorama geral da época (contextualização);

Características visuais predominantes nas obras (em itens);

Principais artistas (nomes);

Obras mais significativas (quatro obras, em resolução de 300 dpi), devendo constar:

2.4.1. Autor;

2.4.2. Título da obra;

2.4.3. Data;

2.4.4. Dimensões;

2.4.5. Onde a obra está localizada atualmente.

O resultado final deste estudo foi impresso como protótipo e atualmente encontra-se pronto, aguardando Editoras que possam publicá-lo sem que isto acarrete custos à organizadora e / ou aos co-autores do trabalhoi.

\section{Para publicação eletrônica:}

De acordo com os trabalhos apresentados pelos alunos (em disquetes e impressos), organização cronológica dos verbetes dos Movimentos Artísticos;

Padronização da apresentação do estudo e análise de cada movimento, com os verbetes dentro do seguinte formato:

Nome do Movimento Artístico e Período (data de início e fim ao lado do nome);

Verbete: características visuais predominantes nas obras (em itens);

Palavras-chave

Principais artistas (nomes);

Obras mais significativas (quatro obras, em resolução de 72 dpi):

2.3.1. Autor;

2.3.2. Título da obra;

2.3.3. Data;

2.3.4. Dimensões;

2.3.5. Onde a obra está localizada atualmente. 
O resultado final deste estudo para publicação eletrônica encontrase pronto, aguardando que a PUC-Campinas divulgue-o através de seu site, em área reservada ao Núcleo de Pesquisa e Extensão do CLC - Centro de Linguagem e Comunicaçãoii.

\section{Resultados esperados}

Através do desenvolvimento deste estudo, foram propostos e atingidos os seguintes objetivos:

Estimular e desenvolver no aluno o interesse pela pesquisa, assim como a responsabilidade e a integridade de informações constantes nos trabalhos, inerentes ao profissional de qualquer setor;

Valorizar o estudo e o aprofundamento das teorias que fundamentam os Movimentos Artísticos na área das Artes Visuais e do Design, buscando-se a contextualização dos mesmos na história, além de demonstrar a importância de cada uma das teorias abordadas por este estudo, conhecê-las, e contextualizadas cronologicamente;

Aprofundar os conhecimentos nas áreas de Teoria e História da Arte, junto aos alunos;

Divulgar os estudos e pesquisas que vêm sendo desenvolvidos além da grade curricular da Faculdade de Artes Visuais da PUC-Campinas.

Abrir novas vertentes a partir do desdobramento do presente estudo, após sua conclusão.

\section{Cronograma}

(proposto e rigorosamente cumprido em todas as suas etapas)

\begin{tabular}{|l|l|l|l|l|l|l|l|l|l|l|l|l|l|}
\hline & \multicolumn{9}{|c|}{2005} & \multicolumn{7}{|c|}{ 2006 } \\
\hline ATIVIDADE & AGO & SET & OUT & NOV & DEZ & JAN & FEV & MAR & ABR & MAI & JUN & JUL \\
\hline Lev Dados & $\mathrm{X}$ & $\mathrm{X}$ & $\mathrm{X}$ & $\mathrm{X}$ & $\mathrm{X}$ & $\mathrm{X}$ & $\mathrm{X}$ & $\mathrm{X}$ & & & & \\
\hline Org. Dados & & & $\mathrm{X}$ & $\mathrm{X}$ & $\mathrm{X}$ & & & & $\mathrm{X}$ & $\mathrm{X}$ & $\mathrm{X}$ & $\mathrm{X}$ \\
\hline Trab texto & $\mathrm{X}$ & $\mathrm{X}$ & $\mathrm{X}$ & $\mathrm{X}$ & $\mathrm{X}$ & $\mathrm{X}$ & $\mathrm{X}$ & $\mathrm{X}$ & & & & \\
\hline Tr. Imagem & $\mathrm{X}$ & $\mathrm{X}$ & $\mathrm{X}$ & $\mathrm{X}$ & $\mathrm{X}$ & $\mathrm{X}$ & $\mathrm{X}$ & $\mathrm{X}$ & & & & \\
\hline Conclusão & & & $\mathrm{X}$ & & & & $\mathrm{X}$ & $\mathrm{X}$ & $\mathrm{X}$ & $\mathrm{X}$ & & \\
\hline Apres impr & & & & $\mathrm{X}$ & & & & $\mathrm{X}$ & $\mathrm{X}$ & $\mathrm{X}$ & $\mathrm{X}$ & \\
\hline Apres míd & & & & $\mathrm{X}$ & & & & $\mathrm{X}$ & $\mathrm{X}$ & $\mathrm{X}$ & $\mathrm{X}$ & \\
\hline
\end{tabular}




\section{Bibliografia}

ARGAN, Giulio Carlo. Arte e crítica de arte. Lisboa: Imprensa Universitária e Editorial Estampa, 1988.

BONFAND, Alain. A Arte Abstrata. Campinas, SP: Papirus Editora, 1994.

COSTA, C. Questões de Arte. São Paulo: Moderna, 1999.

CHIPP, Herschel B. Teorias da Arte Moderna. São Paulo: Martins Fontes, 1988.

HEARTNEY, Eleanor. Pós-Modernismo. São Paulo: Cosac \& Naify Edições, 2002.

LASSALLE, Helène.A Arte no Século XX. Do após-guerra ao Beaubourg. São Paulo: Martins Fontes, 1986.

STANGOS, Nikos. Conceitos da Arte Moderna. Rio de Janeiro: Zahar Editor, 1991.

ATLAN, H. e outros. Idéias Contemporâneas. São Paulo: Ática, 1989.

DUARTE JÚNIOR, João Francisco. O que é Beleza. São Paulo: Editora Brasiliense, 1986.

OSTROWER, F. Criatividade e Processos de Criação Artística. Petrópolis: Vozes, 1978.

SALLES, C. A. Gesto Inacabado. Processo de Criação Artística. São Paulo: FABESP / Anna Blume, 1998. 


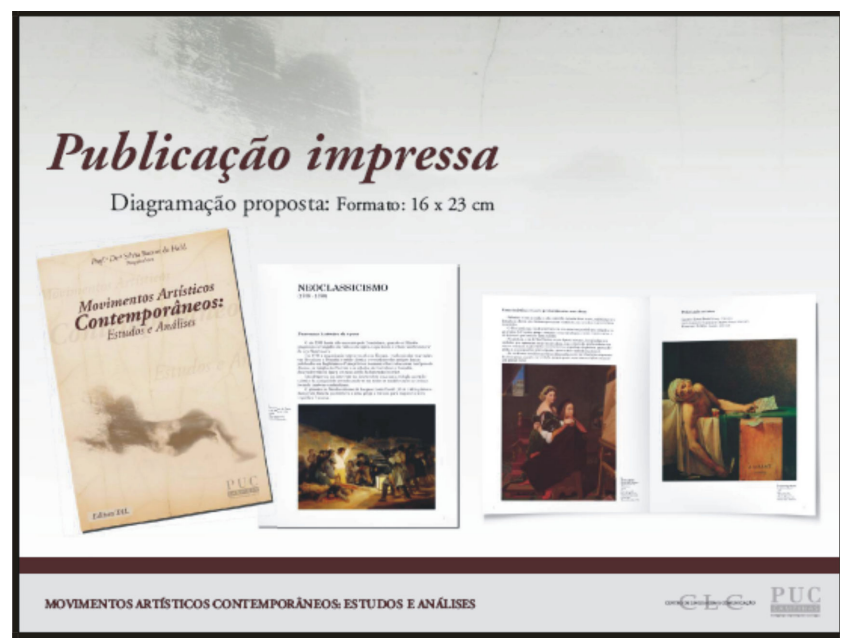

i Proposta para publicação impressa do trabalho "Movimentos Artísticos Contemporâneos: Estudos e Análises"

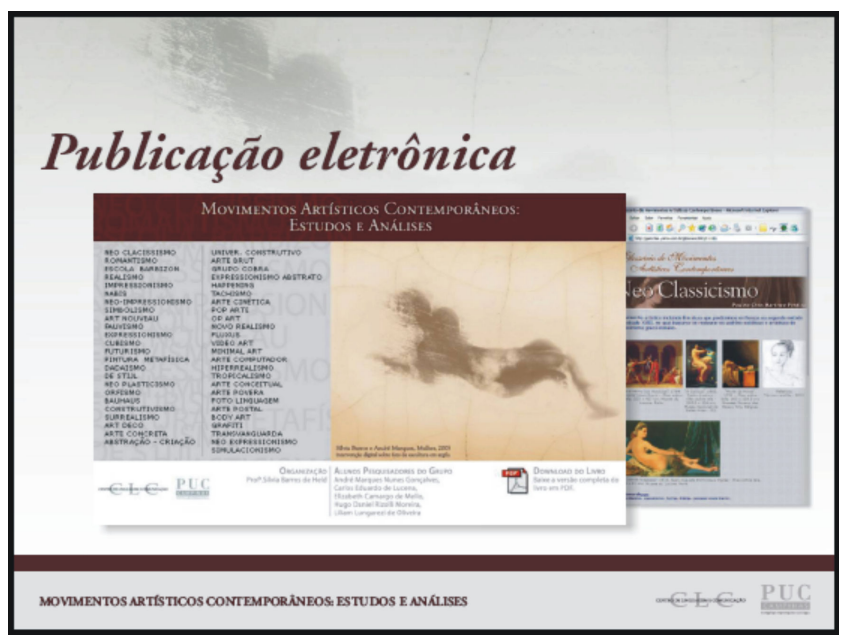

ii Proposta apresentada para publicação eletrônica 